EESTI NSV TEADUSTE AKADEEMIA TOIMETISED. 22. KOIDË KEEMIA * GEOLOOGIA. 1973, NR. 4

ИЗВЕСТИЯ АКАДЕМИИ НАУК ЭСТОНСКОИ ССР. ТОМ 22 ХИМИЯ * ГЕОЛОГИЯ. 1973, Na 4

удК $547.461 ; 543.544$

ЭМИЛИЯ МЯННИК, О. ИКОНОПИСЦЕВА, А. ФОМИНА, А. МЯННИК

\title{
ПРИМЕНЕНИЕ КОМПЛЕКСОВ ВКЛЮЧЕНИЯ С МОЧЕВИНОЙ ДЛЯ РАЗДЕЛЕНИЯ ДИМЕТИЛОВЫХ ЭФИРОВ ДИКАРБОНОВЫХ КИСЛОТ НОРМАЛЬНОГО СТРОЕНИЯ И $\alpha$-МЕТИЛИЗОМЕРОВ
}

Способность мочевины образовывать комплексы включения с достаточно длинноцепочными соединениями нормального строения различных гомологических рядов $\left[{ }^{1,2}\right]$ в последнее время широко используется для разделения соединений нормального и изостроения $\left[{ }^{3,4}\right]$.

В настоящем сообщении излагаются результаты исследований применимости метода комплексообразования с мочевиной для разделения диметиловых эфиров дикарбоновых кислот (ДМЭ ДКК) и их $\alpha$-метилизомеров, а также для концентрации и препаративного выделения соединений изостроения в широких фракциях ДМЭ ДКК.

Работа проведена с фракциями ДМЭ янтарной, глутаровой, адипиновой и пимелиновой кислот, выделенных ректификацией широкой смеси ДМЭ сланцевых ДКК [5]. По данным газохроматографического анализа, взятые фракции содержат 92-95\% компонента нормального строения и $4-6 \% \alpha$-метилизомера. Кроме того, в работе использована фракция азелаиновой и себациновой кислот.

Получение комплексов проводилось по следующей методике. В трехгорлую колбу с обратным холодильником, термометром и мешалкой помещали фракцию ДМЭ ДКК и мочевину в молярном соотношении $1: 5,4-8,1$ (в зависимости от длины цепи исходного эфира) и прибавляли $91,6 \%$ метанола от веса мочевины [6]. Смесь перемешивали 1 ч при $75-80^{\circ} \mathrm{C}$ до полного растворения мочевины, затем медленно охлаждали до комнатной температуры. Осадок комплекса отфильтровывали, промывали диэтиловым эфиром, и смесь растворителей (метанола и диэтилового эфира) отгоняли. Вновь выпавший осадок комплекса отфильтровывали, промывали диэтиловым эфиром, и эфир отгоняли. Остаточные ДМЭ ДКК поступали на следующую ступень комплексообразования. При этом проверялась устойчивость комплексов ДМЭ адипиновой и пимелиновой кислот по отношению к диэтиловому эфиру. Осадок комплекса I ступени помещали в делительную воронку и промывали 300 мл диэтилового эфира. После отгонки эфира в случае фракции ДМЭ адипиновой кислоты было получено 2,6 и в опыте с фракцией ДМЭ пимелиновой кислоты $4,4 \%$ от связанного в комплекс вещества. Анализ экстракта фракции ДМЭ пимелиновой кислоты показал наличие в нем 95,5\% компонента нормального строения и $1,3 \%$ ДМЭ $\alpha$-метилпимелиновой кислоты. Судя по количеству и составу отмытых эфиров, можно заключить, что диэтиловый эфир заметного влияния на разложение комплексов ДМЭ ДКК с мочевиной не оказывает. 


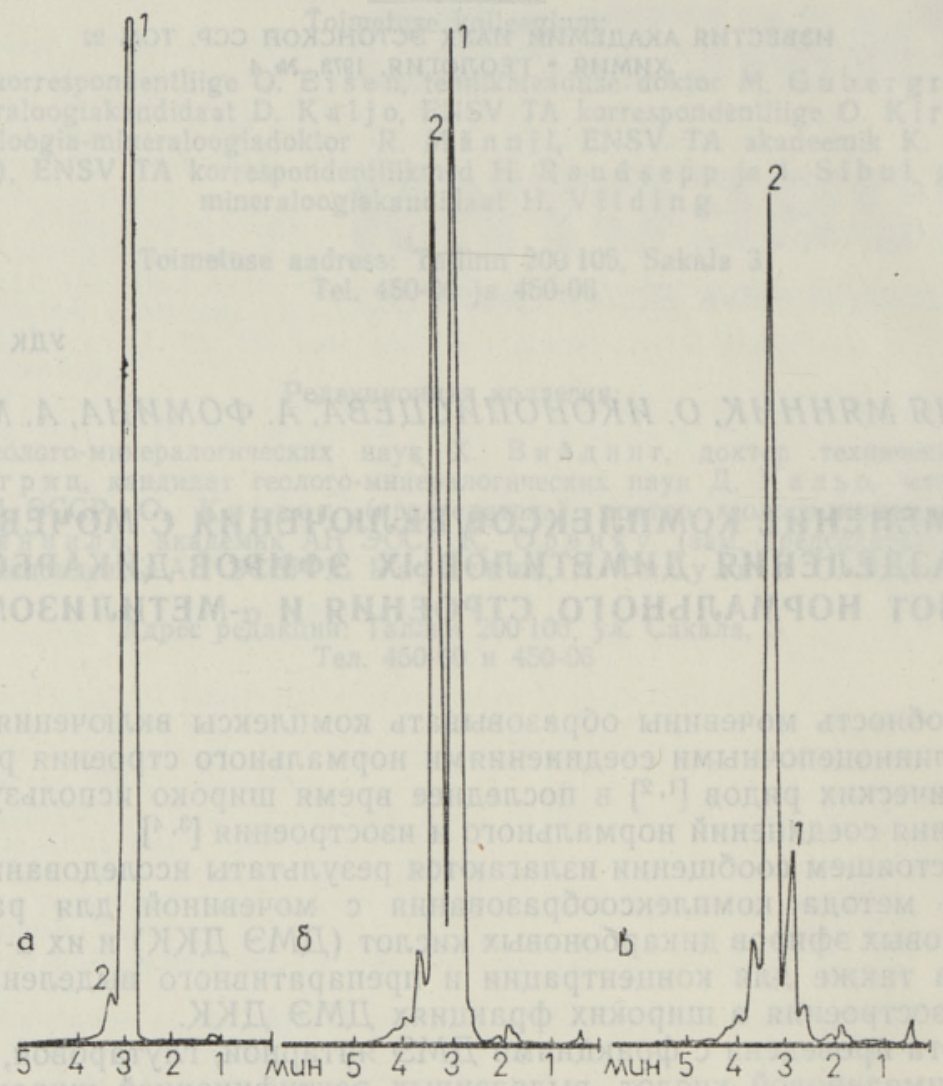

Рис. 1. Хроматограммы исходной фракции ДМЭ $\mathrm{C}_{6}(a)$, второй (б) и пятой (в) ступеней комплексообразования с мочевиной на апиезоне $L$ при $170^{\circ} \mathrm{C}$. 1 - ДМЭ нормальной адипнновой кислоты; 2 - дМЭ $\alpha$-метиладипиновой

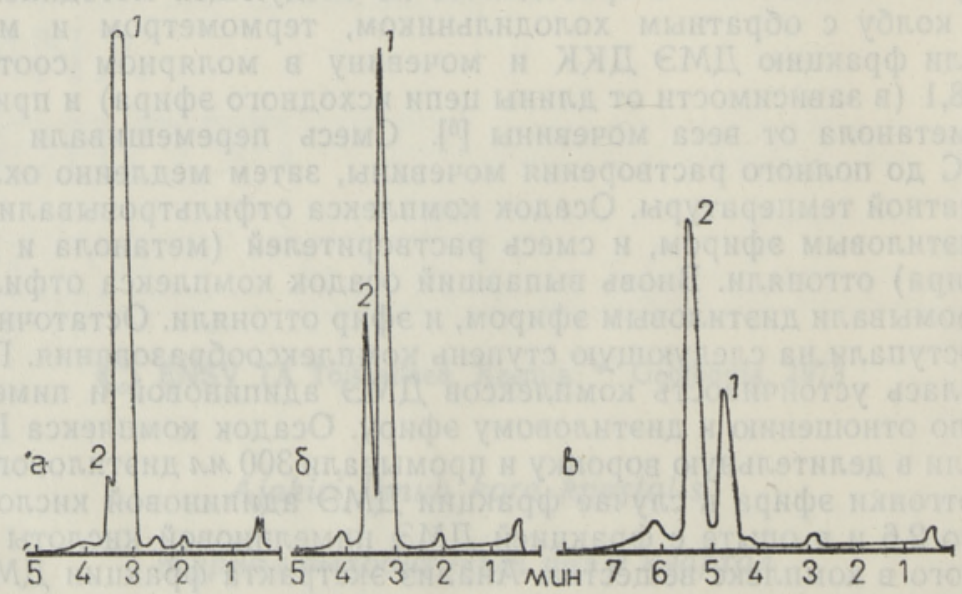

Рис. 2. Хроматограммы исходной фракции ДМЭ $\mathrm{C}_{7}(a)$, второй (б) и пятой $(в)$ ступеней комплексообразования с мочевиной на апиезоне $L$ при $180(a, \sigma)$ и $170^{\circ} \mathrm{C}(8)$.

1 - дМэ нормальной адипиновой кислоты; 2 - дмэ ж-метиладипиновой кислоты. 
Анализ фракций, полученных в результате комплексообразования, проводился методом газо-жидкостной хроматографии. Условия анализа: хроматограф фирмы «Willy Giede», колонка 2 м/6 мм, твердый носитель - хромосорб $W(0,20-0,25 \mu . \mu)$, скорость газа-носителя (гелия) $120 \mathrm{M} /$ мин, температура колонки $150,160,170$ и $180^{\circ}$ для эфиров янтарной, глутаровой, адипиновой и пимелиновой кислот соответственно.

Ступенчатое проведение опытов комплексообразования иллюстрируется данными табл. 1 и рис. $1,2$.

\section{Таблица I}

Результаты ступенчатого комплексообразования с мочевиной фракций ДМЭ ДКК

\begin{tabular}{|c|c|c|c|c|}
\hline $\begin{array}{l}\text { Исходная } \\
\text { фракция } \\
\text { ДМЭ ДКК }\end{array}$ & $\begin{array}{l}\text { Ступень } \\
\text { комплек- } \\
\text { сообра- } \\
\text { зования }\end{array}$ & $\begin{array}{c}\text { Компонент } \\
\text { нормаль- } \\
\text { ного строе- } \\
\text { ния, \% } \\
\end{array}$ & $\begin{array}{r}\alpha \text {-Метил- } \\
\text { изомер, \% }\end{array}$ & \begin{tabular}{|c} 
Осажден- \\
ный с моче- \\
виной ДМЭ \\
ДКК, \%
\end{tabular} \\
\hline $\mathrm{C}_{4}$ & $\begin{array}{l}\mathrm{I} \\
\mathrm{II}^{*} \\
\mathrm{III}^{*} \\
\mathrm{IV}^{*}\end{array}$ & \multicolumn{3}{|c|}{$\begin{array}{rrr}92,2 & 5,7 & \\
90,7 & 8,3 & 23,3 \\
88,7 & 10,5 & - \\
83,7 & 12,2 & 17,1 \\
82,4 & 12,3 & 14,7\end{array}$} \\
\hline $\mathrm{C}_{5}$ & $\begin{array}{l}\text { I } \\
\text { II } \\
\text { III* } \\
\text { IV }\end{array}$ & $\begin{array}{l}95,0 \\
\overline{-} \\
90,9 \\
86,8\end{array}$ & $\begin{array}{l}\frac{4,3}{-} \\
\overline{8,6} \\
7,2\end{array}$ & $\begin{array}{l}22,3 \\
19,4 \\
13,3\end{array}$ \\
\hline $\mathrm{C}_{6}$ & $\begin{array}{l}\text { I } \\
\text { II } \\
\text { III } \\
\text { IV } \\
\mathrm{V}^{*}\end{array}$ & $\begin{array}{l}94,7 \\
79,2 \\
45,8 \\
24,1 \\
20,0 \\
15,3\end{array}$ & $\begin{array}{r}4,1 \\
16,3 \\
40,7 \\
46,0 \\
50,0 \\
66,8\end{array}$ & $\begin{array}{l}82,7 \\
72,9 \\
49,1 \\
\overline{19,1}\end{array}$ \\
\hline 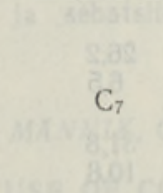 & $\begin{array}{l}\text { I } \\
\text { II } \\
\text { III } \\
\text { IV } \\
\mathrm{V}^{*}\end{array}$ & $\begin{array}{l}93,3 \\
87,4 \\
64,8 \\
36,9 \\
32,2 \\
28,2\end{array}$ & $\begin{array}{r}3,9 \\
10,5 \\
30,5 \\
38,7 \\
47,4 \\
57,6\end{array}$ & $\begin{array}{l}72,8 \\
78,3 \\
46,6 \\
25,0 \\
12,5\end{array}$ \\
\hline
\end{tabular}

* Двукратное увеличение метанола.

Как видно из таблицы, ДМЭ янтарной и глутаровой кислот связываются мочевиной лишь в незначительных количествах (до 23,3\% от веса исходной фракции). После четырехступенчатого комплексообразования содержание эфиров нормального строения снижается от $92,2-95,0$ до $82,4-86,8 \%$. Содержание $\alpha$-метилянтарной и $\alpha$-метилглутаровой кислот возрастает до $7,2-12,3 \%$. Это указывает на слабое и примерно одинаковое взаимодействие нормальных и разветвленных эфиров янтарной и глутаровой кислот с мочевиной. Двукратное увеличение количества метанола в опытах (ступени, отмеченные в табл. 1 звездочкой) и понижение температуры кристаллизации до $-5 \div-10^{\circ}$ существенно не влияют на образование комплексов.

Иные результаты были получены в опытах с фракциями ДМЭ адипиновой и пимелиновой кислот. Здесь по мере проведения ступенчатого комплексообразования процент компонента нормального строения умень- 
шился до $15,3-28,2 \%$, в то время как содержание ДМЭ $\alpha$-метиладипиновой и $\alpha$-метилпимелиновой кислот увеличилось до $57,6-66,8 \%$. При этом количество связанного с мочевиной эфира убывает от ступени к ступени. Это связано, по-видимому, с увеличением содержания в смеси $\alpha$-метилизомеров, которые затрудняют заполнение компонентами нормального строения тончайших цилиндрических каналов гексагональной кристаллической решетки мочевины.

Полученные результаты свидетельствуют о том, что метод комплексообразования с мочевиной позволяет разделять ДМЭ ДКК на компоненты нормального строения и $\alpha$-метилизомеры, начиная с 6 атомов углерода в цепи.

Проведение опытов комплексообразования с мочевиной фракций ДМЭ азелаиновой и себациновой кислот показало, что, помимо $\alpha$-метилизомеров, таким способом можно концентрировать триметиловые эфиры трикарбоновых кислот и метиловые эфиры бензолкарбоновых кислот в смесях ДМЭ ДКК (табл. 2).

\section{Таблица 2}

Изменение состава фракции эфиров азелаиновой и себациновой кислот после обработки мочевиной

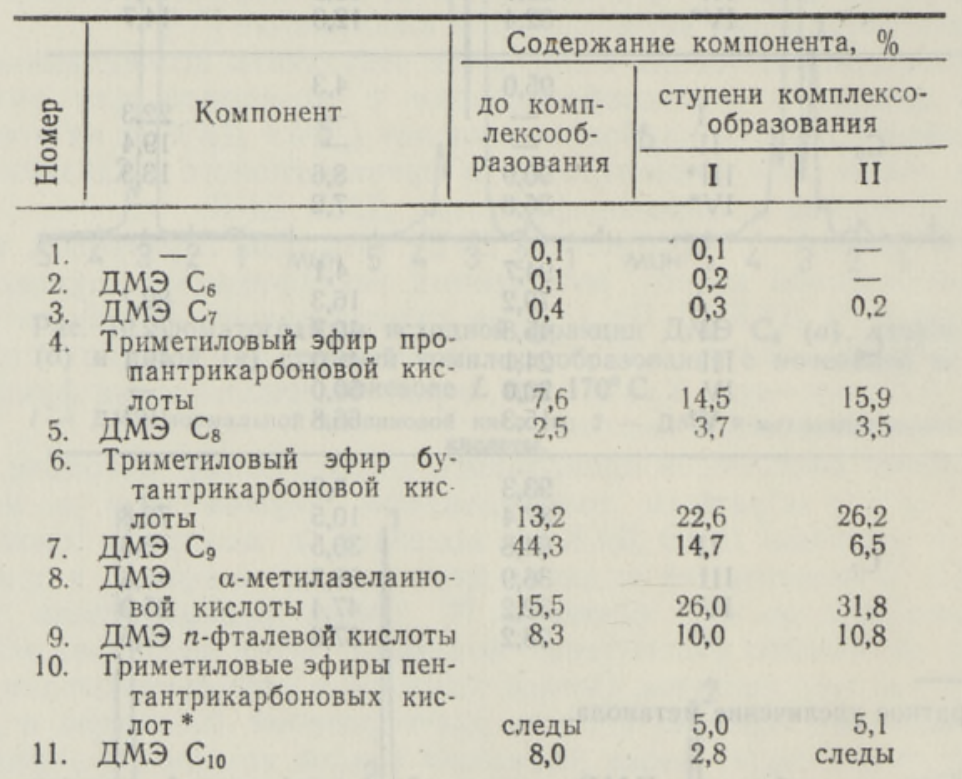

* Смесь триметиловых эфиров $\beta, \gamma$-изомеров пентантрикарбоновой кислоты.

При разложении комплекса ДМЭ пимелиновой кислоты I ступени хлороформом в аппарате Сокслета был получен ДМЭ пимелиновой кислоты 99,1\%-ной чистоты. Выход его составлял около $73 \%$ от веса исходной фракции. Эти данные открывают возможность применения метода для выделения дорогостоящих индивидуальных ДМЭ на основе сланцевых ДКК. 


\section{Выводы}

1. Исследована применимость комплексов включения с мочевиной для разделения ДМЭ ДКК нормального строения и $\alpha$-метилизомеров.

2. Разделение возможно при наличии в цепи молекулы кислоты 6 атомов углерода и более. ДМЭ янтарной и глутаровой кислот обра . зуют или малостабильные комплексы, или не образуют их совсем.

3. Показано,что из фракций ДМЭ сланцевых ДКК могут быть получены индивидуальные эфиры адипиновой и пимелиновой кислот марки «प».

\section{ЛИТЕРАТ У РА}

1. S chlenk W., Liebig's Ann. Chem., 565, 204 (1949).

2. S w e r n D., Ind. Eng. Chem., 39, 126 (1955).

3. Stej aru D., Pope scu R., Rev. Chim., 20, No. 10 (1969).

4. Coleman J. E., Knight H. B., Swern D., J. Am. Chem. Soc., 74, No. 19 (1952).

5. М янник Э. И., Фомин а А. С., Мянни к А. О., Химия твердого топлива, № 3 , 106 (1971).

6. А арна А. Я., К анн Ю. М., Мянник А. О., Тр. Таллинск. политехн. ин-та, Cep. A, № 254, 3 (1967).

$\begin{array}{cc}\text { Институт химии } & \text { Поступила в редакцию } \\ \text { Академии наук Эстонской СCP } & 26 / \mathrm{VI} 1972\end{array}$

EMILIA MANNIK, O. IKONOPISTSEVA, A. FOMINA. A. MANNIK

\section{KARBAMIIDIKOMPLEKSIDE KASUTAMISEST DIKARBOKSUULHAPETE DIMETUOLESTRITE LAHUTAMISEKS NENDE $\alpha$-METUOLISOMEERIDEST}

Artiklis on esitatud andmed dikarboksüülhapete dimetüülestrite ja nende $\alpha$-metüülisomeeride ning dimetüülestrite laiades fraktsioonides sisalduvate isoühendite karbamiidkompleksidega kontsentreerimise ja preparatiivse eraldamise kohta.

Käsitletakse kukersiidi kerogeenist sünteesitud merivaik-, glutaar-, adipiin-, pimeliin-, aselaiin- ja sebatsiinhapete kompleksühendite moodustumist dimetüülestrite fraktsioonidega.

\section{EMILIA MANNIK, O. IKONOPISTSEVA, A. FOMINA, A. MANNIK \\ THE USE OF COMPLEX COMPOUNDS WITH UREA FOR THE SEPARATION OF DIMETHYL ESTERS OF DICARBOXYLIC ACIDS WITH A NORMAL CARBON CHAIN AND $\alpha$-METHYLISOMERS}

In this paper the data about the concentrating and preparative separation of the $\alpha$-methylisomers and isomeric compounds from fractions of dimethyl esters of the dicarboxylic acids by urea complex compounds are presented. The formation of the urea complex compounds with fractions of the dimethyl esters of the succinic, glutaric, adipinic, pimelic acids and the fraction of the azelaic and sebacic acids synthesized from the organic part of oil-shale kukersite has been investigated. 